\title{
Pediatric Emergency Appendectomy and 30-Day Postoperative Outcomes in District General Hospitals and Specialist Pediatric Surgical Centers in England, April 2001 to March 2012
}

\author{
Retrospective Cohort Study
}

\author{
Stefano Giuliani, MD, PhD, ${ }^{*}$ Elizabeth V. Cecil, PhD, $\dagger$ Nadja Apelt, MD, ${ }^{*} \ddagger$ Michael Sharland, MD, $\S$ \\ and Sonia Saxena, MD $\dagger$
}

\begin{abstract}
Objective: To compare trends in pediatric emergency appendectomy and adverse surgical outcomes between district general hospitals (DGHs) and specialist pediatric centers (SPCs).

Background: In the past decades in England, a significant reduction in the number of children operated by adult general surgeons has raised concerns about their surgical outcomes compared with specialist pediatric surgeons. Methods: Using Hospital Episode Statistics, we analyzed patient-level data between April 2001 and March 2012. Main inclusion criteria were children younger than 16 years admitted to NHS-England hospitals for an emergency appendectomy. Main outcomes were annual age-sex adjusted appendectomy rates and postoperative risk of readmission, complication, and reintervention.

Results: A total of 83,679 emergency pediatric appendectomies were performed in 21 SPCs and 183 DGHs in England. SPCs performed only 18\% of these operations $(15,002)$. Annual age-sex standardized appendectomy rates fell from 87 to 68 per 100,000 population at an estimated $2 \%$ (rate ratio, 0.98 ) fall per annum. This was accompanied by a national annual increased risk of negative appendectomy, complication, reintervention, and readmission (adjusted odds ratio: 1.02, 1.03, 1.04, and 1.06, respectively). Children who had appendectomies in DGHs had 28\% more negative appendectomies, $11 \%$ more complications, and $11 \%$ more readmissions than those in SPCs. Postoperative length of stay was double in SPCs compared with DGHs (median, 4 vs 2 days).

Conclusions: Major reductions in the number of pediatric emergency appendectomies in England over the past decade were associated with an overall increase in adverse surgical outcomes. Children operated in DGHs have more reinterventions, complications, and negative appendectomy rates than those operated in SPCs.
\end{abstract}

Keywords: children, emergency appendectomy, hospital volume, postoperative outcome, trends

From the *Department of Paediatric and Neonatal Surgery, St George's Healthcare NHS Trust and University of London, London, UK; †Department of Primary Care and Public Health, Imperial College London, London, UK: $\ddagger$ Kinderchirurgische Klinik und Poliklinik, Dr. von Haunersches Kinderspital, Munich, Germany; and §Department of Paediatric Infectious Disease, St George's Healthcare NHS Trust and University of London, London, UK.

Disclosure: E.C. and S.S. are funded by National Institute for Health Research (Career Development Fellowship CDF-2011-04-048). This article presents independent research commissioned by the National Institute for Health Research (NIHR). The views expressed in this publication are those of the authors and not necessarily those of the NHS, the NIHR, or the Department of Health. The authors declare no conflicts of interest.

Reprints: Stefano Giuliani, MD, PhD, Department of Paediatric and Neonatal Surgery, St George's Healthcare NHS Trust, and University of London, Blackshaw Rd, London, SW17 0QT, UK. E-mail: stefano.giuliani@nhs.net. Copyright (C) 2015 Wolters Kluwer Health, Inc. All rights reserved. ISSN: 0003-4932/14/26105-0821

DOI: $10.1097 /$ SLA.0000000000001099
(Ann Surg 2016;263:184-190)

$P$ ostoperative complications in children undergoing appendectomy are reportedly worse in district settings compared with specialist centers in many countries. ${ }^{1-3}$

Reducing numbers of emergency appendectomy procedures carried out in children have further raised concerns about the quality and safety of care in district general hospitals (DGHs) compared with specialist units in England. ${ }^{4}$ Acute appendicitis is the most common surgical emergency in children, with a lifetime risk of $7 \%$ to $8 \%$ and an incidence of up to 20 to 30 cases per 10,000 children per year between 10 and 17 years of age. ${ }^{5}$ Children with appendicitis need an acute admission to hospital and an emergency appendectomy performed by an expert surgeon with either an open or a laparoscopic technique. Clinical outcomes are dependent on many factors including timely diagnosis and severity of disease at presentation. ${ }^{6,7}$ Later presentations with localized or diffuse peritonitis carry a higher risk of postoperative complications including wound infection, intraabdominal abscess, and adhesional small bowel obstruction of around $15 \%$ to $25 \%$ and a need for hospital readmission of about $4 \%$ to $5 \%{ }^{8,9}$ The skill of the operator in knowing when to intervene can influence the rate of negative appendectomy that exposes children to possible iatrogenic harms. These need to be weighed against the risks of perforation in case of delays. Diagnosis can be more difficult in younger children, impacting adversely on outcomes. ${ }^{10}$

In recent years, DGHs have treated the majority of children presenting with acute appendicitis and specialist pediatric centers (SPCs) usually manage younger and more complex cases either primarily or by hospital transfer. ${ }^{11,12}$ Falls in the number of children having elective and emergency general pediatric surgery in English DGHs from April 1994 to March 2005 have raised concerns about a potential reduction of pediatric operating and emergency care skills among staff in DGHs compared with SPCs where an increasing number of operations in children are carried out. ${ }^{13}$

In 2013, The Royal College of Surgeons of England issued guidance on quality and safety standards for pediatric surgery, which were particularly aimed at general surgeons who have a low volume of pediatric operations. ${ }^{14} \mathrm{~A}$ clear definition of a low-volume surgeon in children's surgery has never been published. In addition, an international decline in the incidence of appendicitis has been reported, but it is unclear whether this trend applies to England, and if so, what has been the impact on surgical management and outcomes in emergency appendectomies. ${ }^{15,16}$

We used the hospital episodes statistics (HES) database to compare trends in number of procedures and 30-day postoperative outcomes of pediatric emergency appendectomies performed in DGHs and SPCs in the past decade. 


\section{METHODS}

\section{Data Sources}

The HES database records all finished consultant episodes of all admissions to NHS hospitals in England. The main reason for admission or "primary diagnosis" is coded using the International Classification of Diseases, Tenth Revision (ICD-10) and procedures (OPCS codes-Office of Population Censuses and Surveys Classification of Interventions and Procedures, 4th edition). We extracted data on children younger than 16 years who had an appendectomy procedure coded during their admission to hospital (H01) (Appendix 1) between April 1, 2001 and March 31, 2012. We assigned children to 4 developmental age bands: 0 to 3,4 to 7,8 to 11 , and 12 to 15 years.

We identified children who had undergone a laparoscopic appendectomy as those who had the following secondary procedure codes: Y75.1 or Y75.2. Laparoscopic procedures were recorded in HES only starting from 2006. Negative appendectomy was defined by the OPCS code H01.3. Year was defined as the financial year (April to March) of the appendectomy. We assigned a proxy marker of severity of appendicitis as no, localized, and generalized peritonitis.

We identified 21 hospitals that provide specialist pediatric care in England (Appendix 2).

\section{Main Outcomes}

Our main outcomes were annual adjusted appendectomy rates and risk of 30-day postoperative adverse outcome (readmissions, complications, reinterventions, and negative appendectomies).

We defined the rate of appendectomy as the number of appendectomy procedures per year divided by the population, for each age band, using midyear estimates from the Office of National Statistics.

We defined readmissions as a readmission of a child within 30 days after the index operation. We calculated the odds of readmission as the number of children readmitted divided by the number of children with no readmission.

We developed code lists to define postoperative complications using $I C D$ - 10 codes (Appendix 3). We combined immediate surgical complications (no readmission) with delayed surgical complications (readmission within 30 days).

We defined reinterventions, immediate and delayed, using OPCS codes (Appendix 4).

\section{Statistical Analysis}

We compared baseline characteristics of the study population between the trust hospital groups, using $\chi^{2}$ tests for categorical and $t$ tests for continuous variables. We calculated age-sex standardized rates using 2001 as the reference population.

We investigated trends in national appendectomy rates using negative binomial regression, a method that accounts for overdispersion of the outcome variable. The trend was reported as an annual rate ratio.

Logistic regression analysis was used to investigate the risk of readmission for postoperative complications and reinterventions; negative appendectomies; and the proportion of procedures carried out laparoscopically. A binary variable indicating the trust hospital group where the appendectomy was performed and year were included in the model.

We controlled for the child's age group, sex, and severity of disease and investigated interactions between covariates, comparing models using likelihood ratio tests. $P$ values of less than 0.05 were considered statistically significant. We used Stata SE Version 11 (StataCorp, College Station, TX) for the data analysis.

\section{RESULTS}

Between April 2001 and March 2012, 83,679 appendectomies were performed in a population of more than 10 million children younger than 16 years in England. Eighteen percent $(15,002)$ of pediatric appendectomies were performed in SPCs.

Annual appendectomy rates increased with age from 3.8 [95\% confidence interval (CI), 3.5-4.0] per 100,000 children younger than 4 years to 150 (95\% CI, 149-152) per 100,000 children ages 12 to 15 years.

Between 2001-2002 and 2011-2012, age-sex standardized annual pediatric appendectomy rates decreased from 87 (85-89) to $68(67-70)$ per 100,000 population at an estimated $2 \%$ fall per annum (rate ratio, 0.98; 95\% CI, 0.98-0.98) (Fig. 1).

The proportion of emergency appendectomies in children younger than 8 years that were performed in an SPC increased between 2001-2002 and 2011-2012, from 22\% (239/1085) to $34 \%$ (272/790) (Table 1). A higher proportion of children who had an appendectomy performed in an SPC had generalized peritonitis compared with those in a DGH [39\% (451/1146) vs 21\% (1108/ 5362), respectively, $P<0.001]$. SPCs performed more laparoscopic procedures than DGHs. In 2011 to 2012, 55\% (630/1146) of SPCs' appendectomies were performed laparoscopically compared with $25 \%$ (1358/5362) in DGHs, $P$ value of less than 0.001. In 2001 to 2002, 48\% (67/141) of DGHs in England performed fewer than 50 pediatric appendectomies a year by 20011 to 12 , and this had increased to $66 \%(80 / 121), P=0.002$.

The proportion of SPCs performing less than 50 appendectomies a year also increased between 2001-2002 and 2011-2012, from $35 \%(7 / 20)$ to $47 \%$ (10/21); due to the small number of SPCs, there was no evidence to suggest that the increase was statistically significant, $P$ value of 0.412 .

\section{Adverse Surgical Outcomes}

During the study period, adverse surgical outcomes increased significantly for both DGHs and SPCs (Table 2).

Negative appendectomy rates increased from 11 (903/8590) to 13 per 100 children (861/6508) between 2001-2002 and 2011-2012 and were estimated to be increasing at $2 \%$ per year over the study period [adjusted odds ratio (OR), 1.02; 95\% CI, 1.01-1.02] (Table 3). Children treated in an SPC were $28 \%$ less likely to have a negative appendectomy than in a DGH (adjusted OR, 0.72; 95\% CI,

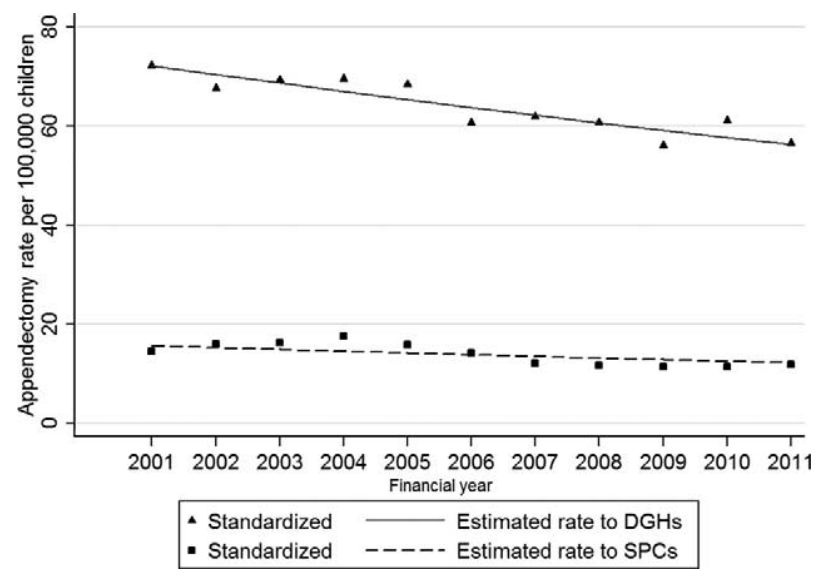

FIGURE 1. Age-sex standardized and model estimated annual pediatric appendectomy rates in DGHs and SPCs by financial year 2001-2002 to 2011-2012 in England. 
TABLE 1. Characteristics of Children Younger Than 16 Years Undergoing Appendectomy, Disease Severity on Presentation, and Type of Emergency Pediatric Appendectomy Procedure Performed in DGHs and SPCs in England in 2001-2002 and 2011-2012

\begin{tabular}{|c|c|c|c|c|}
\hline & \multicolumn{2}{|c|}{ DGHs* } & \multicolumn{2}{|c|}{$\mathrm{SPCs}^{*}$} \\
\hline & 2001-2002 & 2011-2012 & 2001-2002 & 2011-2012 \\
\hline & $\mathrm{n}=\mathbf{7 1 5 1}$ & $\mathrm{n}=\mathbf{5 3 6 2}$ & $n=1439$ & $n=1146$ \\
\hline $0-3$ & $52(0.7)$ & $14(0.3)$ & $50(3.5)$ & $80(7.0)$ \\
\hline $4-7$ & $794(11)$ & $504(9)$ & 189 (13) & $192(17)$ \\
\hline $8-11$ & $2784(39)$ & $1979(37)$ & $560(39)$ & $355(31)$ \\
\hline Acute appendicitis & $5754(80)$ & $4161(77)$ & $1106(77)$ & $660(58)$ \\
\hline Localized peritonitis & $189(3)$ & $93(2)$ & $28(2)$ & $35(3)$ \\
\hline Generalized peritonitis & $1208(17)$ & $1108(21)$ & $305(21)$ & $451(39)$ \\
\hline Laparoscopic procedure $\dagger, \mathrm{n}(\%)$ & - & $1358(25)$ & - & $630(55)$ \\
\hline
\end{tabular}

${ }^{*}$ There were 183 DGHs and 21 SPCs in this analysis.

$\dagger$ Coding for laparoscopic procedures introduced in 2006.

0.68-0.77). Independent risk factors for negative appendectomies were being female and of younger age.

Complication rates increased from 14 (1244/8590) to 18 (1186/6508) per 100 children over the study period, an estimated increase of 3\% per year [adjusted OR, 1.03 (95\% CI, 1.02-1.03)]. Children treated in an SPC were $11 \%$ less likely to have complications [adjusted OR, 0.89 (95\% CI, 0.85-0.93)]. The risk of surgical complications was greater in girls and younger children.

Readmission rates increased from 6.5 (559/8590) to 10 (650/ $6508)$ per 100 children over the study period, with an estimated $4 \%$ increase per year [adjusted OR, 1.04 (95\% CI, 1.04-1.05)]. Children treated in an SPC were $11 \%$ less likely to have a postoperative readmission [adjusted OR, 0.89 (95\% CI, 0.83-0.95)]. Independent risk factors for readmission were being female, being of younger age, and presenting with generalized peritonitis.

Around $2 \%$ of appendectomies resulted in a reintervention (1726/83679). Reinterventions were estimated to be increasing at a rate of $6 \%$ per year [adjusted OR, 1.06 (95\% CI, 1.04-1.07)]. There was no evidence that children treated in SPC were less likely to have a postoperative reintervention after adjusting for confounders [adjusted OR, 0.93 (95\% CI, 0.83-1.06)].
Between 2001-2002 and 2011-2012, postoperative length of stay fell in DGHs from a median of 3 days (interquartile range, 2-4) to 2 days (interquartile range, $2-3$ ). The fall in mean length of stay was statistically significant at $P$ value of less than 0.001 . Whereas, between 2001-2002 and 2011-2012, SPCs' length of stay increased from median of 3 days (3-5) to 4 days (2-6).

\section{DISCUSSION}

\section{Principal Findings}

In the past decade, emergency appendectomy rates in England among children younger than 16 years fell from 87 to 68 per 100,000 children. The national rate of negative appendectomies, complications, readmissions, and reinterventions increased annually at $2 \%, 3 \%, 4 \%$, and $6 \%$, respectively, over the study period. Over the same period, more procedures have been carried out in specialist centers. In 2001 to 2002, 22\% of emergency appendectomies in children younger than 8 years were performed in an SPC and by 2011 to 2012 , it was $34 \%$. Children presenting to SPCs are $11 \%$ more likely to present with peritonitis and stay twice as long in hospital than those presenting to DGHs. Despite this, children who had

TABLE 2. Postoperative Outcomes for Pediatric Appendectomies in DGHs and SPCs in Children Younger Than 16 Years in England, 2001-2002 and 2011-2012

\begin{tabular}{|c|c|c|c|c|}
\hline & \multicolumn{2}{|c|}{ DGHs* } & \multicolumn{2}{|c|}{ SPCs* } \\
\hline & 2001-2002 & 2011-2012 & $2001-2002$ & 2011-2012 \\
\hline & $\mathbf{n}=\mathbf{7 1 5 1}$ & $\mathrm{n}=\mathbf{5 3 6 2}$ & $n=1439$ & $n=1146$ \\
\hline Standardized admission rates $\dagger(95 \%$ CI $)$ & $72.2(70.5-73.8)$ & $56.5(55-58)$ & $14.5(13.8-15.3)$ & $11.9(11.2-12.6)$ \\
\hline Negative appendectomy, n (\%) & $782(11)$ & $731(14)$ & $121(8)$ & $130(11)$ \\
\hline 30-d complications, $\ddagger$ n (\%) & $1061(14.8)$ & $1005(18.7)$ & $183(12.7)$ & $181(15.8)$ \\
\hline Readmissions, $\S \mathrm{n}(\%)$ & $473(6.6)$ & $530(9.9)$ & $86(6.0)$ & $120(10.5)$ \\
\hline Reintervention, n (\%) & $109(1.5)$ & $138(2.6)$ & $29(2.0)$ & $38(3.3)$ \\
\hline Postoperative length of stay median (IQR) & $3(2-4)$ & $2(2-3)$ & $3(3-5)$ & $4(2-6)$ \\
\hline
\end{tabular}

${ }^{*} 183$ DGHs and 21 SPCs in this analysis.

$\nmid$ Rates standardized using 2001-2002 as the reference population and are shown as rates per 100,000 children.

$\ddagger$ Immediate (during index procedure admission) and delayed (within $30 \mathrm{~d}$ of the index procedure) complications.

$\S$ Readmissions within $30 \mathrm{~d}$ of the index procedure. 
TABLE 3. Adjusted Odds Ratios of Postoperative Outcomes in Children Younger Than 16 Years Between April 2001 and March 2012, in England

\begin{tabular}{|c|c|c|c|c|c|c|c|c|}
\hline & \multicolumn{2}{|c|}{$\begin{array}{c}\text { Negative } \\
\text { Appendectomy }\end{array}$} & \multicolumn{2}{|c|}{ Complications* } & \multicolumn{2}{|c|}{ Readmissions $\dagger$} & \multicolumn{2}{|c|}{ Re-intervention $\ddagger$} \\
\hline & OR & $95 \% \mathrm{CI}$ & OR & $95 \% \mathrm{CI}$ & OR & $95 \% \mathrm{CI}$ & OR & $95 \% \mathrm{CI}$ \\
\hline DGHs@ & 1.00 & & 1.00 & & 1.00 & & 1.00 & \\
\hline SPCs§ & 0.72 & $0.68-0.77$ & 0.89 & $0.85-0.93$ & 0.89 & $0.83-0.95$ & 0.94 & $0.83-1.06$ \\
\hline Year|| & 1.02 & $1.01-1.02$ & 1.03 & $1.02-1.03$ & 1.04 & $1.04-1.05$ & 1.06 & $1.04-1.07$ \\
\hline Boys & 1.00 & & & & & & & \\
\hline Girls & 2.26 & $2.16-2.35$ & 1.65 & $1.59-1.71$ & 1.15 & $1.10-1.21$ & & \\
\hline \multicolumn{9}{|l|}{ Age group, yr } \\
\hline $0-3$ & 0.42 & $0.32-0.56$ & 0.92 & $0.77-1.10$ & 1.72 & $1.43-2.07$ & 1.47 & $1.07-2.02$ \\
\hline $4-7$ & 0.44 & $0.40-0.48$ & 0.79 & $0.74-0.85$ & 1.32 & $1.22-1.43$ & 1.24 & $1.07-1.44$ \\
\hline $8-11$ & 0.75 & $0.71-0.78$ & 0.87 & $0.84-0.91$ & 1.12 & $1.06-1.18$ & 1.07 & $0.96-1.19$ \\
\hline $12-15 \ddagger$ & 1.00 & & 1.00 & & 1.00 & & 1.00 & \\
\hline \multicolumn{9}{|c|}{ Disease severity (baseline acute appendicitis) } \\
\hline Acute appendicitis $\uparrow$ & & & 1.00 & & 1.00 & & 1.00 & \\
\hline Localized peritonitis & - & - & 1.02 & $0.90-1.15$ & 2.65 & $2.32-3.02$ & 10.39 & $8.85-12.20$ \\
\hline Generalized peritonitis & - & - & 0.79 & $0.75-0.83$ & 2.15 & $2.03-2.27$ & 3.39 & $3.06-3.77$ \\
\hline \multicolumn{9}{|c|}{$\begin{array}{l}\text { *Immediate (during index procedure admission) and delayed (within } 30 \text { days of the index procedure) complications (see Appendix } 3 \text { ). } \\
\dagger \text { Readmissions within } 30 \text { days of the index procedure. } \\
\vdots \text { Immediate (during index procedure admission) and delayed (within } 30 \text { days of the index procedure) reintervention. } \\
\text { §A total of } 183 \text { DGHs and } 21 \text { SPCs in this analysis. } \\
\text { ॠBaseline group. } \\
\| \text { Year is continuous variable, with April } 2001 \text { as baseline. }\end{array}$} \\
\hline
\end{tabular}

undergone their appendectomy in a DGH had higher risks of negative appendectomies, complications, and readmissions than those who had undergone operations in SPCs $(28 \%, 11 \%, 11 \%$, respectively).

\section{Study Limitations}

HES data have been shown to be a useful tool for exploring relationships between health care quality and clinical outcomes. ${ }^{17}$ The size and population coverage of this national data set adds strength to our study. Ours is the first study to investigate adverse pediatric appendectomy outcomes nationally, and a design strength is that we were able to link hospital admissions and procedures for the same child within the 30 days of postoperative period.

Nevertheless, there are a number of important limitations to our study. In common with all large observational studies using routine data, our findings are subject to bias and confounding as a result of inaccuracies in data coding and incomplete data sets. Coding has improved over the study period with the introduction of payment by result, ${ }^{18}$ which could in part explain the increasing trend in postoperative complications, but we also observed an increase in readmissions, which would not be influenced by clinical coding issues.

We defined "SPC" via the trust code, and in cases in which a trust has multiple sites providing emergency care, some procedures may be misclassified; however, misclassification would only be in a very small proportion of cases.

We adjusted for a child's age and sex and found that deprivation was not associated with postoperative complications, readmission, and reintervention. We adjusted for disease severity; however, HES data are not based on pathology report but on the clinical information completed by surgical teams that communicate intraoperative findings. We did not control for comorbidities. Children with more severe peritonitis were more likely to be seen in an SPC, and we feel that this would also be the case in comorbid children, ultimately diluting the effect of SPCs on the outcomes.

\section{Findings in Relation to Previous Studies}

Our data are in line with other reports from the United States and Canada where general surgeons perform most of the pediatric emergency appendectomies and pediatric surgeons usually operate on younger and sicker children. ${ }^{19,20}$ The incidence of acute appendicitis and the rate of emergency appendectomies have been declining for some time before our study in England and other developed countries, but the reasons are still not clear. ${ }^{21}$ Advances in diagnostic skills, increased use of radiology (computed tomography and ultrasonography), and prompt antibiotic treatment of infection may have contributed to an overall reduction in the need for emergency appendectomies.

International benchmarks published in a meta-analysis of pediatric data from contemporary studies from the US and Canadian hospitals showed considerably better pediatric emergency appendectomy outcomes than those from hospitals in England. ${ }^{22}$ In particular, our results showed an overall negative appendectomy rate of $11 \%$, which is up to 3 times higher than that of the United States (3\%-5\%); a 30-day postoperative complication rate of $17.5 \%$ compared with an overall morbidity rate of $6.4 \%$ in the United States; and the 30-day readmission rate of $7.9 \%$ that compares poorly against the $1 \%$ to $4 \%$ reported in North American studies. ${ }^{22,23}$ These differences in the scale of postoperative outcomes between England and other countries may in part be explained by differences in case mix and health coverage. We recommend this as an area for future research.

We have demonstrated that SPCs have better 30-day postoperative outcomes with lower risk of readmission and reintervention than DGHs. Possible explanations are that SPCs may have a stronger consultant presence in the operating theatre, better training of specialist pediatric surgeons than general adult surgeons, organization and adherence to evidence-based clinical care protocols and pathways for acute appendicitis commonly used by pediatric surgeons, and better pediatric facilities in specialist settings than operative equipment in DGHs. ${ }^{24}$

Moreover, in the last decade, there has been a significant reduction in caseload, particularly for general surgeons who perform procedures in children and also for specialist pediatric surgeons ( $-33.4 \%$ and $-17.8 \%$ for DGHs and SPCs, respectively). Despite overall falls, there is an increasing trend for specialist pediatric surgeons to perform a higher number of procedures in children 
younger than 8 years. Our findings suggest that SPCs have better surgical outcomes despite a more complex caseload illustrated by higher rates of generalized peritonitis and lower negative appendectomy rates. This differs with findings from a smaller multicenter study of 19 SPCs and 54 DGHs that also found a higher negative appendectomy rate in DGHs and more complex caseload in SPCs but which found no differences in surgical outcomes after adjusting for case mix and consultant presence. ${ }^{4}$

DGHs had significantly shorter mean length of stay than SPCs (2 vs 4 days) after adjusting for age, disease severity, and negative appendectomy rate. This again contrasts with US practice where length of stay in admissions under the care of pediatric surgeons is shorter. ${ }^{1,2}$ One explanation for this difference could be more cautious discharge criteria for younger children and adherence to pediatric protocols of care stipulating duration of postoperative antibiotic and analgesia.

Recent recommendations from The Royal College of Surgeons of England have suggested that only children older than 5 years should be operated on close to home in a DGH. ${ }^{25,26}$ The relative convenience of providing emergency surgical care close to home needs to be balanced with the capability to deliver high quality of care in terms of safety and clinical outcomes. Hence, our findings of an overall decline in the quality of surgical care in the last decade in DGHs and SPCs are of major concern. Diagnostic accuracy (negative appendectomy rate), minimally invasive surgical technique (laparoscopy), length of stay, and 30-day postoperative outcomes (complications, readmissions, and reoperations) are widely used as key indicators of care quality in an emergency surgery procedure with low mortality such as appendectomy. ${ }^{27}$

\section{What Can Be Done to Improve the Adverse Outcomes Reported in This Study?}

The diagnosis of acute appendicitis remains largely a matter of clinical judgment and relies heavily on the skills of the attending surgeon. However, children with acute appendicitis are not the same as young adults with the same medical condition. Younger children are more difficult to assess and present in atypical ways. ${ }^{28}$ For example, those younger than 6 years have a shorter time from onset of symptoms to perforation. Differential diagnosis of other causes of abdominal pain, such as gastroenteritis and adenomesenteritis that are common in children, can be more challenging in young children because of communication difficulties and less focal signs. Admission to hospital for observation can be a key diagnostic technique yet hard to justify amid constraints to discharge patients and limit health care costs. ${ }^{29,30}$ In modern evidence-based medicine, clinical pathways combining validated scores for pediatric acute appendicitis (ie, Alvarado and Samuel's Pediatric Appendicitis Score-PAS) with the use of ultrasound have shown a diagnostic accuracy ranging up to $90 \%$ to $94 \% .{ }^{31,32}$ Moreover, large pediatric American centers, with increased utilization of routine imaging studies and specialist surgeons, have shown negative appendectomy rate as low as $2 \%$ to $3 \%$ without any increase in perforation rates. ${ }^{33}$ In England, the progressive decreasing number of pediatric emergency appendectomies in DGHs may be a reason for the discrepancy, with the aforementioned benchmarking data affecting the quality of surgical care. In this scenario, another possible factor related to the outcomes in DGHs is the level of consultant involvement from diagnosis to discharge. One regional study comparing the surgical management of pediatric appendicitis in a specialist center, Birmingham Children's Hospital, with a local DGH found a higher proportion $(45 \%)$ of the most senior grade of surgeon to be actively taking part in the operation compared with only $9 \%$ of cases in the $\mathrm{DGH}^{34}$ Diagnostic and specialist surgical pediatric skills may explain a high rate of negative appendectomy and complications together with the low usage of laparoscopy in DGHs in England. In our study, it was not possible to confirm the grade of the surgeon present during the operation, but recent national data showed that overall consultant presence in theater was less than $25 \%$, and this was directly associated with increased used of laparoscopy and reduction in 30-day morbidity. ${ }^{12}$

In the United States, two-thirds of pediatric appendectomies are performed in hospitals that perform less than 1 appendectomy per week. ${ }^{35}$ Our findings from English hospitals are consistent with this, showing that $66.4 \%$ of DGHs perform less than 50 operations per year. Few studies have attempted to determine the relationship between hospital volume and outcome in pediatric emergency appendectomy, but our findings of a lower-negative appendectomy rate for higher-volume hospitals is consistent with systematic review data of pediatric surgery, showing that surgeons' experience and specialist hospitals have better reported outcome measures. ${ }^{36}$

\section{Implications and Future Research}

Over the past 2 decades, there has been a considerable debate about who should perform children's emergency surgery in England. ${ }^{37,38}$ The Children's Surgical Forum of The Royal College of Surgeons has stated as the overarching principle of pediatric surgical care in the country: the need for children to be "treated safely and as close to home as possible" and the unfeasibility of managing the majority of emergency children's surgery in tertiary pediatric centers. ${ }^{14}$ The fact that more than $80 \%$ of pediatric appendectomies are performed in DGHs and that the majority of these hospitals have a low and decreasing volume of children's surgery suggests that this condition could be a national priority for a quality improvement program. Effective managed clinical networks between DGHs and SPCs with an annual individual surgeon audit of children's surgery (incorporating histopathological outcomes) are one tool that could be used to precisely define and compare epidemiology and outcomes nationally. This accountability may in turn lead to an increased level of supervision for trainees, from diagnosis to discharge, and to an overall improvement of the quality of the training.

\section{CONCLUSIONS}

This study has identified significant concerns around clinical outcomes in a procedure of decreasing frequency. Robust audit tools, improved national guidelines, and strong central commissioning will be required to bring outcomes up to international comparator data. There is also a need to consider national benchmarks for outcome comparison in emergency children's surgery to guarantee a minimum quality of surgical care in the different hospitals in England.

\section{ACKNOWLEDGMENTS}

The authors thank Dr Paul Bathke for a revision of the last version of the article.

S.G. had the original idea for the study and worked up the background and design with M.S., S.S., E.C., and N.A. E.C. performed the analysis. S.G. wrote the first draft and all authors saw and approved subsequent and final drafts.

\section{REFERENCES}

1. Alexander F, Magnuson D, DiFiore J, et al. Specialty versus generalist care of children with appendicitis: an outcome comparison. J Pediatr Surg. 2001;36:1510-1513.

2. Kokoska ER, Minkes RK, Silen ML, et al. Effect of pediatric surgical practice on the treatment of children with appendicitis. Pediatrics. 2001;107:12981301.

3. Collins HL, Almond SL, Thompson B, et al. Comparison of childhood appendicitis management in the regional paediatric surgery unit and the district general hospital. J Pediatr Surg. 2010;45:300-302. 
4. Tiboni S, Bhangu A, Hall NJ. Outcome of appendicectomy in children performed in paediatric surgery units compared with general surgery units. Br J Surg. 2014;101:707-714

5. Aarabi S, Sidhwa F, Riehle KJ, et al. Pediatric appendicitis in New England: epidemiology and outcomes. J Pediatr Surg. 2011;46:1106-1114.

6. Tsioplis C, Brockschmidt C, Sander S, et al. Factors influencing the course of acute appendicitis in adults and children. Langenbecks Arch Surg. 2013;398:857-867.

7. To T, Langer JC. Does access to care affect outcomes of appendicitis in children?-a population-based cohort study. BMC Health Serv Res. 2010;10:250.

8. Tiwari MM, Reynoso JF, Tsang AW, et al. Comparison of outcomes of laparoscopic and open appendectomy in management of uncomplicated and complicated appendicitis. Ann Surg. 2011;254:927-932.

9. Markar SR, Blackburn S, Cobb R, et al. Laparoscopic versus open appendectomy for complicated and uncomplicated appendicitis in children. J Gastrointest Surg. 2012;16:1993-2004.

10. Bansal S, Banever GT, Karrer FM, et al. Appendicitis in children less than 5 years old: influence of age on presentation and outcome. Am J Surg. 2012;204:1031-1035.

11. Pye JK. Survey of general paediatric surgery provision in England, Wales and Northern Ireland. Ann R Coll Surg Eng. 2008;90:193.

12. National Surgical Research Collaborative. Multicentre observational study of performance variation in provision and outcome of emergency appendicectomy. Br J Surg. 2013;100:1240-1252.

13. Tanner S. Trends in children's surgery in England. Arch Dis Child. 2007;92:664-667.

14. Children's Surgical Forum of The Royal College of Surgeons of England. Standards for children's surgery. Available at: https://www.rcseng.ac.uk/ publications/docs/standards-in-childrens-surgery. Published 2013. Accessed August 5, 2014.

15. Donnelly NJ, Semmens JB, Fletcher DR, et al. Appendicectomy in Western Australia: profile and trends, 1981-1997. Med J Aust. 2001;175:15-18.

16. Ilves I, Paajanen HE, Herzig KH, et al. Changing incidence of acute appendicitis and nonspecific abdominal pain between 1987 and 2007 in Finland. World J Surg. 2011;35:731-738.

17. Bottle A, Millett C, Xie Y, et al. Quality of primary care and hospital admissions for diabetes mellitus in England. I Ambul Care Manage. 2008;31:226-238.

18. Commission A. Improving coding, costing and commissioning: annual report on the Payment by Results data assurance programme 2010/11. Available at: http://www.audit-commission.gov.uk/2011/09/improving-coding-costingand-commissioning-annual-report-on-the-payment-by-results-data-assurance-programme-201011/. Published 2011. Accessed August 5, 2014.

19. Somme S, To T, Langer JC. Effect of subspecialty training on outcome after pediatric appendectomy. J Pediatr Surg. 2007;42:221-226.

20. Emil SG, Taylor MB. Appendicitis in children treated by pediatric versus general surgeons. J Am Coll Surg. 2007;204:34-39.

21. Kang JY, Hoare J, Majeed A, et al. Decline in admission rates for acute appendicitis in England. Br J Surg. 2003;90:1586-1592.
22. Oyetunji TA, Ong'uti SK, Bolorunduro OB, et al. Pediatric negative appendectomy rate: trend, predictors, and differentials. J Surg Res. 2012; $173: 16-20$.

23. Raval MV, Deans KJ, Rangel SJ, et al. Assessing quality in pediatric surgerythe limited role of appendectomy as the optimal target. J Pediatr Surg. 2013;48:2313-2319.

24. Bensard DD, Hendrickson RJ, Fyffe CJ, et al. Early discharge following laparoscopic appendectomy in children utilizing an evidence-based clinical pathway. J Laparoendosc Adv Surg Tech A. 2009;19:S81-S86.

25. The Royal College of Surgeons of England. Surgery for children: delivering a first class service. Available at: https://www.rcseng.ac.uk/publications/docs/ CSF.html. Published 2007. Accessed August 5, 2014.

26. Association of Paediatric Anaesthetists, Association of Surgeons for Great Britain and Ireland, British Association of Paediatric Surgeons, Royal College of Paediatrics and Child Health, Senate of Surgery for Great Britain and Ireland. Joint Statement on General Paediatric Surgery provision in District General Hospitals. London: BAPS; 2006. Available at: www.baps.org.uk/ index.html. Accessed August 5, 2014.

27. Chowdhury MM, Dagash H, Pierro A. A systematic review of the impact of volume of surgery and specialization on patient outcome. $\mathrm{Br} J$ Surg. 2007;94:145-161.

28. Nance ML, Adamson WT, Hedrick HL. Appendicitis in the young child: a continuing diagnostic challenge. Pediatr Emerg Care. 2000;16:160162.

29. Almond SL, Roberts M, Joesbury V, et al. It is not what you do, it is the way that you do it: impact of a care pathway for appendicitis. J Pediatr Surg. 2008;43:315-319.

30. Kosloske AM, Love CL, Rohrer JE, et al. The diagnosis of appendicitis in children: outcomes of a strategy based on pediatric surgical evaluation. Pediatrics. 2004;113:29-34.

31. Saucier A, Huang EY, Emeremni CA, et al. Prospective evaluation of a clinical pathway for suspected appendicitis. Pediatrics. 2014;133:e88-e95.

32. Escriba A, Gamell AM, Fernandez Y, et al. Prospective validation of two systems of classification for the diagnosis of acute appendicitis. Pediatr Emerg Care. 2011;27:165-169.

33. Ponsky TA, Huang ZJ, Kittle K, et al. Hospital- and patient-level characteristics and the risk of appendiceal rupture and negative appendectomy in children. JAMA. 2004;292:1977-1982.

34. Whisker L, Luke D, Hendrickse C, et al. Appendicitis in children: a comparative study between a specialist paediatric centre and a district general hospital. J Pediatr Surg. 2009;44:362-367.

35. Smink DS, Finkelstein JA, Kleinman K, et al. The effect of hospital volume of pediatric appendectomies on the misdiagnosis of appendicitis in children. Pediatrics. 2004;113:18-23.

36. McAteer JP, LaRiviere CA, Drugas GT, et al. Influence of surgeon experience, hospital volume, and specialty designation on outcomes in pediatric surgery: a systematic review. JAMA Pediatr. 2013;167:468-475.

37. Atwell JD, Spargo PM. The provision of safe surgery for children. Arch Dis Child. 1992;67:345-349.

38. McNicol R. Paediatric anaesthesia-who should do it? The view from the specialist hospital. Anaesthesia. 1997;52:513-515. 


\section{APPENDIX 1}

Appendectomy (OPCS4) Codes Selected as Primary Procedure and Laparoscopic Codes Selected as Secondary Procedure in the Index Operation

\begin{tabular}{ll}
\hline OPCS4 Code & \multicolumn{1}{c}{$\begin{array}{c}\text { Description } \\
\text { Appendectomy }\end{array}$} \\
\hline Primary procedure \\
H01.1 & Emergency excision of abnormal appendix and drainage HFQ \\
H01.2 & Emergency excision of abnormal appendix NEC \\
H01.3 & Emergency excision of normal appendix \\
H01.8 & Emergency excision of appendix OS \\
H01.9 & Emergency excision of appendix unspecified \\
\hline
\end{tabular}

Laparoscopic

Secondary procedure (same day)

Y75.1 Laparoscopically assisted approach to abdominal cavity Y75.2 Laparoscopic approach to abdominal cavity NEC

HFQ indicates However Further Qualified; NEC, Not Elsewhere Classified; OPCS4, Office of Population Censuses and Surveys, Classification of Surgical Operations and Procedures, 4th revision; OS, Other specified.

\section{APPENDIX 2}

\begin{tabular}{ll}
$\begin{array}{c}\text { Trust } \\
\text { Trust } \\
\text { Codes for Specialist Pediatric Centers in England }\end{array}$ \\
\hline RA7 & University Hospitals Bristol NHS Foundation Trust \\
RBS & Alder Hey Children's NHS Foundation Trust \\
RCU & Sheffield Children's NHS Foundation Trust \\
RGT & Cambridge University Hospitals NHS Foundation Trust \\
RHM & University Hospital Southampton NHS Foundation Trust \\
RJ1 & Guy's and St. Thomas' NHS Foundation Trust \\
RJ7 & St George's Healthcare NHS Trust \\
RJZ & King's College Hospital NHS Foundation Trust \\
RM1 & Norfolk and Norwich University Hospitals NHS Foundation Trust \\
RNJ & Barts and the London NHS Trust \\
RP4 & Great Ormond Street Hospital for Children NHS Foundation Trust \\
RQ3 & Birmingham Children's Hospital NHS Foundation Trust \\
RQM & Chelsea and Westminster Hospital NHS Foundation Trust \\
RR8 & Leeds Teaching Hospitals NHS Trust \\
RTD & The Newcastle Upon Tyne Hospitals NHS Foundation Trust \\
RTH & Oxford University Hospitals NHS Trust \\
RW3 & Central Manchester University Hospitals NHS Foundation Trust \\
RWA & Hull and East Yorkshire Hospitals NHS Trust \\
RWE & University Hospitals of Leicester NHS Trust \\
RX1 & Nottingham University Hospitals NHS Trust \\
RXH & Brighton and Sussex University Hospitals NHS Trust \\
\hline
\end{tabular}

\section{APPENDIX 3}

Postoperative Complications - International Classification of Diseases, Tenth Revision (ICD-10) Codes

\begin{tabular}{ll}
$\begin{array}{c}\text { ICD-10 } \\
\text { Code }\end{array}$ & \multicolumn{1}{c}{ Description } \\
\hline J95.8 & Postprocedural respiratory disorders, other \\
J95.9 & Postprocedural respiratory disorder, unspecified \\
K56.5 & Intestinal adhesions with intestinal obstruction \\
K56.6 & Other unspecified intestinal obstruction \\
R10 & Abdominal pain \\
T36 & Poisoning by systemic antibiotics \\
T81.0 & Hemorrhage or hematoma complicating a procedure \\
T81.1 & Shock during or resulting from a procedure \\
T81.2 & Accidental puncture and laceration during a procedure \\
T81.4 & Infection after a procedure, not elsewhere classified \\
T81.4 & Disruption of operative wound, not elsewhere classified \\
T81.5 & Foreign body accidentally left in operation wound or body cavity \\
T81.6 & Acute reaction to foreign substance accidentally left during a \\
& procedure \\
T81.8 & Subcutaneous emphysema resulting from a procedure \\
T81.9 & Unspecified complication of a procedure \\
T88.2 & Shock due to anesthesia \\
T88.3 & Malignant hyperthermia due to anesthesia \\
T88.4 & Failed intubation \\
T88.5 & Other complications of anesthesia \\
T88.6 & Anaphylactic shock due to correct drug \\
T88.7 & Unspecified adverse effect of drug or medication \\
T88.8 & Complications of surgical care, other \\
T88.9 & Complication of surgical care, unspecified \\
T99.0 & Postprocedural renal failure \\
T99.1 & Postprocedural urethral stricture \\
Y84.6 & Urinary catheterization as the cause of abnormal reaction \\
& of the patient or of later complications \\
\hline &
\end{tabular}

\section{APPENDIX 4}

\begin{tabular}{ll}
$\begin{array}{l}\text { Reintervention-OPCS4 codes } \\
\text { OPCS4 }\end{array}$ \\
Code & \multicolumn{1}{c}{ Description } \\
\hline G53.2 & Closure of perforation of duodenum NEC \\
G63.3 & Closure of perforation of jejunum \\
G76.2 & Open relief of strangulation of ileum \\
G76.3 & Open relief of obstruction of ileum NEC \\
G78.4 & Closure of perforation of ileum \\
H03.1 & Drainage of abscess of appendix \\
H17.6 & Open relief of obstruction of colon NEC \\
S47.2 & Drainage of lesion of skin NEC \\
T30.1 & Reopening of abdomen and re-exploration of intra-abdominal \\
& operation site and surgical arrest of postoperative bleeding \\
T31.5 & Drainage of anterior abdominal wall \\
T34.2 & Open drainage of pelvic abscess \\
T34.3 & Open drainage of abdominal abscess NEC \\
T41.3 & Freeing of adhesions of peritoneum \\
T41.5 & Freeing of extensive adhesions of peritoneum \\
T42.3 & Endoscopic division of adhesions of peritoneum \\
T45.2 & Image-controlled percutaneous drainage of pelvic abscess \\
T45.3 & Image-controlled percutaneous drainage of abdominal \\
& abscess NEC \\
Y18.1 & Freeing of adhesions of organ NOC \\
\hline NEC indicates Not Elsewhere Classified; NOC, Not Otherwise Classifiable; OPCS4, \\
Office of Population Censuses and Surveys, Classification of Surgical Operations and \\
Procedures, 4th revision.
\end{tabular}

